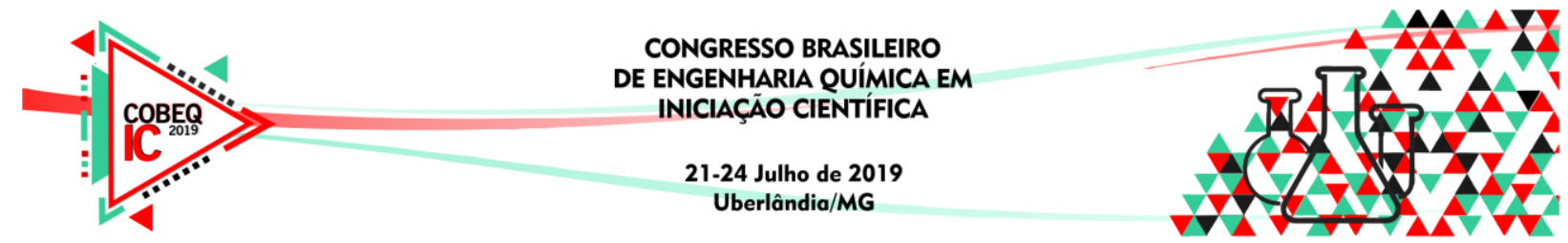

\title{
SIMULAÇÃO DO USO DO LÍQUIDO IÔNICO 1-BUTIL-3- METILIMIDAZÓLIO-TETRAFLUOROBORATONO \\ PARA PRODUÇÃO DE BIOETANOL ANIDRO COM O ASPEN PLUS
}

\author{
L. S. FELIX ${ }^{1}$, M. M. VIEIRA ${ }^{1}$, V.C.V. MEIRELES ${ }^{1}$, E. J. MELO ${ }^{2}$ e J. I. S. SILVA ${ }^{1}$ \\ ${ }^{1}$ Universidade Federal dos Vales do Jequitinhonha e Mucuri, Instituto de Ciência e \\ Tecnologia \\ ${ }^{2}$ Universidade Estadual de Campinas, Faculdade de Engenharia Química \\ E-mail para contato: lidsfelix@gmail.com
}

\begin{abstract}
RESUMO - Os biocombustíveis apresentam-se no cenário global como uma fonte alternativa de energia para os combustíveis fósseis, se destacando pelo caráter renovável e baixos índices de emissão de partículas poluentes ao ambiente. A produção de bioetanol é proveniente do processo de fermentação, no qual é gerada uma mistura multicomponente, de onde o bioetanol anidro é separado. Para obtêlo são necessárias operações como a destilação extrativa, em que solventes são adicionados a fim de promover a "quebra" do azeótropo existente entre o etanol e água. Neste trabalho o líquido iônico [BMIM][BF4] foi utilizado com solvente. A partir do uso da ferramenta computacional Aspen Plus ${ }^{\circledR}$, simulações do processo de destilação extrativa de uma mistura multicomponente composta por etanol, água, ácido acético e álcool isoamílico obteve-se bioetanol anidro. A performance do solvente foi realizada analisando-se os parâmetros operacionais da coluna extrativa, como a razão de refluxo, taxa de destilado e a vazão de solvente. Os resultados obtidos para o 1-butil-3-metilimidazólio-tetrafluoroboratono foram de grau de pureza de 99,7\% em massa com um aproveitamento mínimo de $75 \%$ do bioetanol que é alimentado na coluna extrativa.
\end{abstract}

\section{INTRODUÇÃO}

O cenário mundial requer a utilização de novas formas de energia que atendam a economia e em especial as exigências ambientais de modo sustentável. Neste contexto, ressalta-se a aplicabilidade do biocombustível para suprir tal demanda. Além de ser oriundo de qualquer biomassa, é um combustível renovável e emite menores quantidades de partículas poluentes ao ambiente (MASSOM et al., 2015).

O bioetanol produzido no Brasil é gerado a partir da biomassa de cana-de-açúcar. Uma das etapas fundamentais para a produção de bioetanol é a fermentação na qual é gerado o leite de levedura e o vinho delevedurado (ZANARDI e JÚNIOR, 2016). O vinho gerado no processo de fermentação apresenta natureza multicomponente. Desse material impuro, o bioetanol anidro é separado em grau de pureza de 99,6\% em massa, conforme o Regulamento Técnico ANP n³/2011, por meio da destilação extrativa. O bioetanol anidro tem sido de 


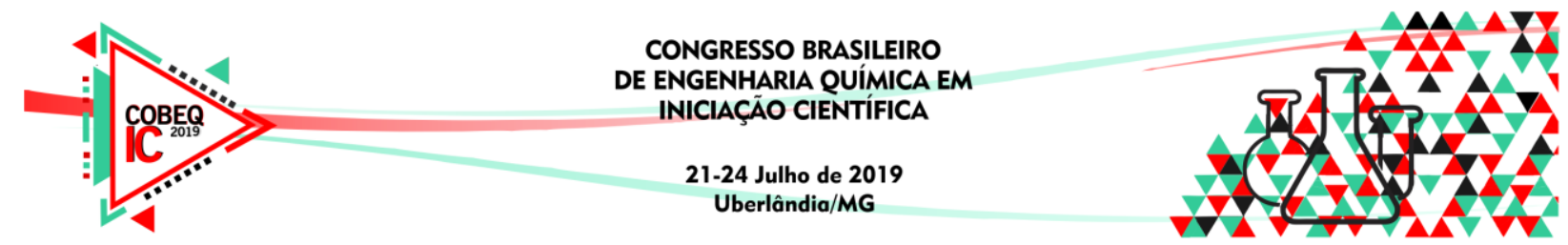

grande interesse em indústrias químicas devido ao seu potencial como solvente para muitos processos (ZUBIR et al., 2017).

$\mathrm{Na}$ destilação extrativa, um solvente é inserido ao sistema, alterando a volatilidade relativa dos componentes, a fim de impedir a formação do azeótropo. Tal processo se destaca pelo seu baixo consumo de energia (ZHU et al., 2016).

Há inúmeros solventes que podem ser aplicados ao sistema bioetanol/água, dentre eles têm-se os líquidos iônicos (LI), chamados de solventes verdes, são constituídos por cátions orgânicos carregados, combinados a ânions orgânicos ou inorgânicos, os quais resultam em uma alteração físico-química, conferindo aos mesmos algumas propriedades físicas importantes, como: estabilidade térmica, alta solvatação, não são inflamáveis ou voláteis, além de ter ponto de fusão inferior a $100^{\circ} \mathrm{C}$ (HAGHIGHI e NIKOOFAR, 2016; EL-NAGAR et al, 2017).

Segundo Ullmann e Elvers (2011) os líquidos iônicos são adequados como material de arraste para grande variedade de sistemas azeotrópicos e que se a água faz parte da mistura azeotrópica, os fatores de separação podem ser alcançados satisfatoriamente, uma vez que os líquidos iônicos são geralmente materiais higroscópicos com uma forte afinidade com a água.

Dessa forma, o presente trabalho, teve como objetivo a da obtenção de bioetanol anidro com uso do solvente [BMIM][BF4] através de simulações do processo de destilação extrativa, utilizando o simulador Aspen Plus ${ }^{\circledR}$.

\section{FORMULAÇÃO DO PROBLEMA}

Neste trabalho, foi utilizado o solvente líquido iônico 1-butil-3-metilimidazóliotetrafluoroborato [BMIM][BF4]. Os cálculos realizados para este trabalho são representados pelo modelo termodinâmico NRTL (Non-Randow Two-Liquid). A mistura multicomponente estudada é composta por etanol, água, ácido acético e álcool isoamílico, e os dados do sistema foram adaptados baseando-se no trabalho da Matugi (2013) como apresentado na Tabela 1.

Tabela 1 - Composição da Mistura Multicomponente

\begin{tabular}{ccc}
\hline Mistura multicomponente & $\begin{array}{c}\text { Fração mássica } \\
\text { (Matugi, 2013) }\end{array}$ & $\begin{array}{c}\text { Fração mássica } \\
\text { (Este trabalho) }\end{array}$ \\
\hline Água & 0,622519 & 0,876000 \\
Etanol & 0,376399 & 0,129000 \\
Álcool isoamílico & 0,000841 & 0,000740 \\
Ácido acético & - & 0,000920 \\
\hline
\end{tabular}

Os parâmetros operacionais utilizados foram ajustados em uma série de simulações para obtenção dos que mais se adequaram ao comportamento do sistema. Para a coluna de destilação simples, foram baseados em Matugi (2013), e para coluna de destilação extrativa 
no trabalho de Rocha et al. (2016). Tais parâmetros são apresentados nas Tabelas 2 e 3, e foram mantidos para as simulações do sistema com o solvente estudado.

Tabela 2 - Parâmetros de Operação da Coluna de Destilação (Coluna 1)

\begin{tabular}{ccc}
\hline Especificações & Matugi (2013) & Presente trabalho \\
\hline Número de estágios de equilíbrio & 7 & 15 \\
Pressão da coluna isobárica (bar) & 1 & 1,0 \\
Condensador & Total & Total \\
Refervedor & Ketlle & Kettle \\
Razão de refluxo & 4,5 & 4 \\
Estágio de alimentação & 3 & 12 \\
Vazão de alimentação (kg/h) & 28535 & 28535 \\
Temperatura de Alimentação $(\mathrm{K})$ & 360 & 360 \\
\hline
\end{tabular}

Tabela 3 - Parâmetros de Operação da Coluna Extrativa (Coluna 2).

\begin{tabular}{ccc}
\hline Especificações & (ROCHA, et al. 2016) & Presente trabalho \\
\hline Temperatura de alimentação do solvente (K) & 353,15 & 360 \\
Pressão de Alimentação do solvente (bar) & 1 bar & 1,5 bar \\
Condensador & Total & Total \\
Número de estágios & 24 & 35 \\
Estágio de alimentação do solvente & 4 & 3 \\
Estágio de alimentação da mistura & 12 & 33 \\
Refervedor & Kettle & Kettle \\
\hline
\end{tabular}

Na Figura 1 um fluxograma de representação do processo pode ser verificado.

Figura 1 - Representação do processo de obtenção de bioetanol anidro no Aspen Plus ${ }^{\circledR}$.

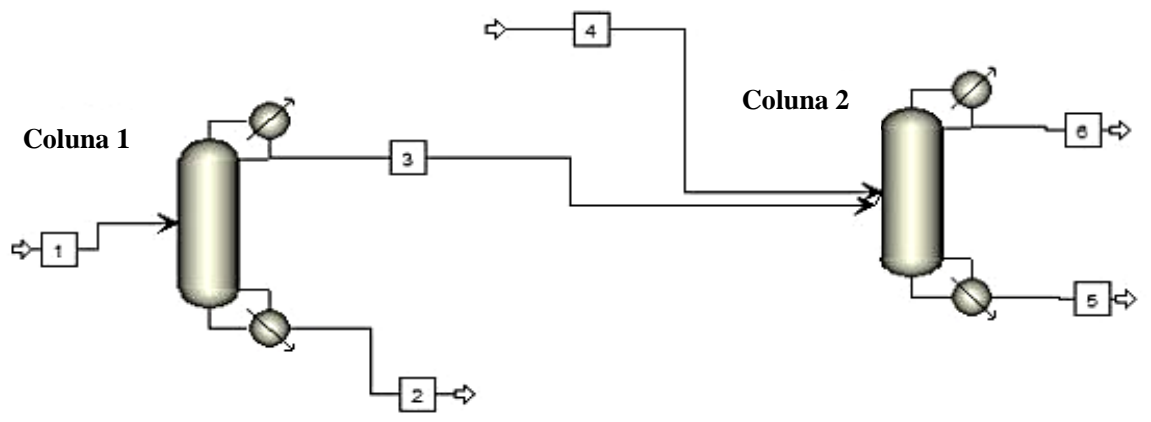




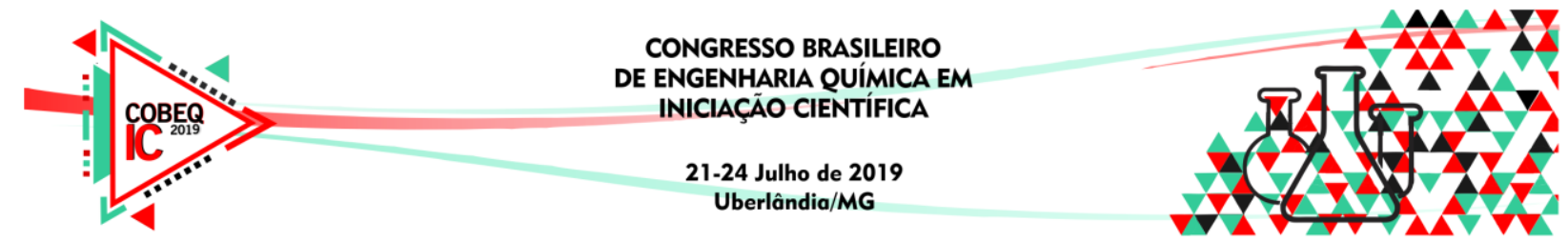

Foi necessário à inserção das propriedades referentes ao líquido iônico no simulador Aspen Plus ${ }^{\circledR}$, por meio dos módulos Pseudocomponent e Dechema, como são apresentados na Tabela 4.

Tabela 4 - Dados inseridos no Aspen Plus ${ }^{\circledR}$ para a simulação com o [BMIM][BF4]

\begin{tabular}{ccc}
\hline Dados utilizados & Valores & Referência \\
\hline Temperatura de Ebulição $(\mathrm{K})$ & 495,2 & Zhu $(2017)$ \\
Densidade $\left(\mathrm{kg} / \mathrm{m}^{3}\right)$ & 1190,0 & Souza et al. $(2018)$ \\
Massa molar $(\mathrm{g} / \mathrm{mol})$ & 226,0 & Zhu $(2017)$ \\
$\mathrm{g}_{\mathrm{ij}}(\mathrm{J} / \mathrm{mol})$ & 5406,9 & Zhu $(2017)$ \\
$\mathrm{g}_{\mathrm{ji}}(\mathrm{J} / \mathrm{mol})$ & 8301,9 & Zhu $(2017)$ \\
$\alpha$ & 0,3 & Zhu $(2017)$ \\
\hline
\end{tabular}

Com a finalidade de avaliar a viabilidade do solvente proposto neste trabalho, foram fixadas as condições padrões que garantissem um processo viável, desta forma fixou-se o grau de pureza do bioetanol anidro em no mínimo 99,7\% em massa e um aproveitamento mínimo de $75 \%$ do bioetanol que é alimentado na coluna de destilação extrativa. A partir de tais condições, manipulou-se a taxa de destilado, razão de refluxo e vazão de solvente até que as condições necessárias fossem atendidas no sistema proposto.

\section{RESULTADOS}

Com base nas simulações é possível observar o comportamento dinâmico da temperatura e da fração mássica das fases líquida e vapor ao longo dos estágios da coluna de destilação extrativa como apresentado na Figura 2.

Figura 2 - Comportamento da a) Temperatura e b) Fração Mássica Líquida e c) Fração

Mássica Vapor para o [BMIM][BF4] na Coluna de Destilação Extrativa.

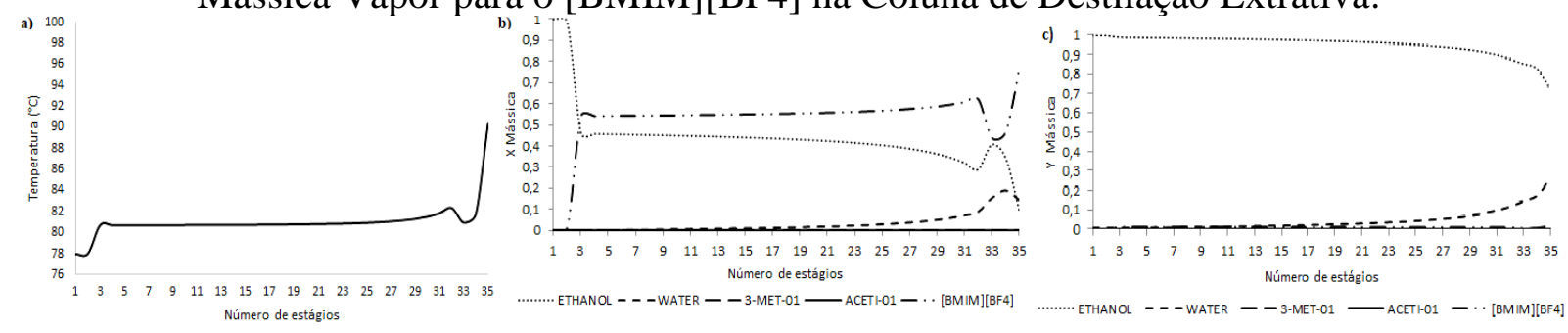

Analisando a coluna extrativa, coluna 2, pode-se analisar o comportamento da temperatura e das frações líquidas e de vapor em função do número de estágios da coluna. Nota-se que a temperatura de trabalho da coluna é mantida superior a temperatura do ponto azeotrópico (cerca de $78,2{ }^{\circ} \mathrm{C}$ ), o que implica na quebra do azeótropo por esse solvente. O pico, expressado no estágio 3, é resultante da corrente de alimentação da mistura etanol-água, que entra a uma temperatura de $79,3{ }^{\circ} \mathrm{C}$. Suplementa-se ainda que, no estágio 33, ocorre a alimentação do líquido iônico que entra na coluna extrativa e no estágio 35 , tende-se a apresentar a maior temperatura da coluna devido a presença do refervedor. As frações líquidas 


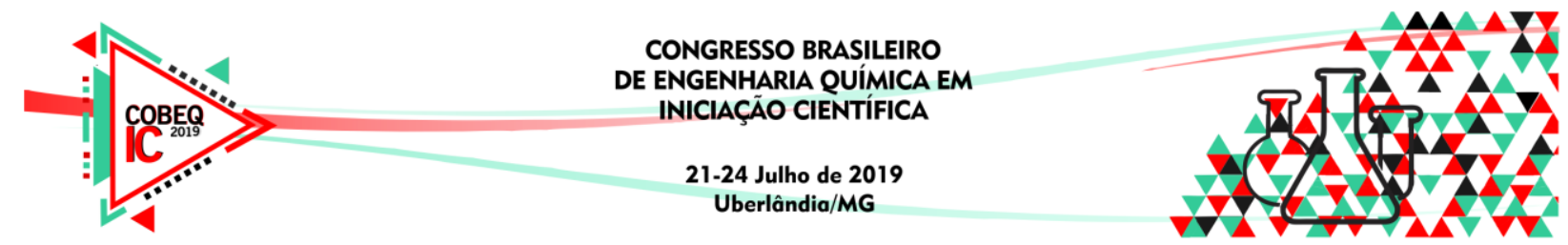

e de vapor comfirmam a quebra do azeótropo, devido a apresentar maiores frações para o etanol no produto de topo e maiores frações de água no produto de fundo.

Figura 3 - Comportamento da pureza do bioetanol, no topo da coluna extrativa, em função da variação da a) vazão de solvente, b) razão de refluxo e c) taxa de destilado no sistema alimentado com [BMIM][BF4].
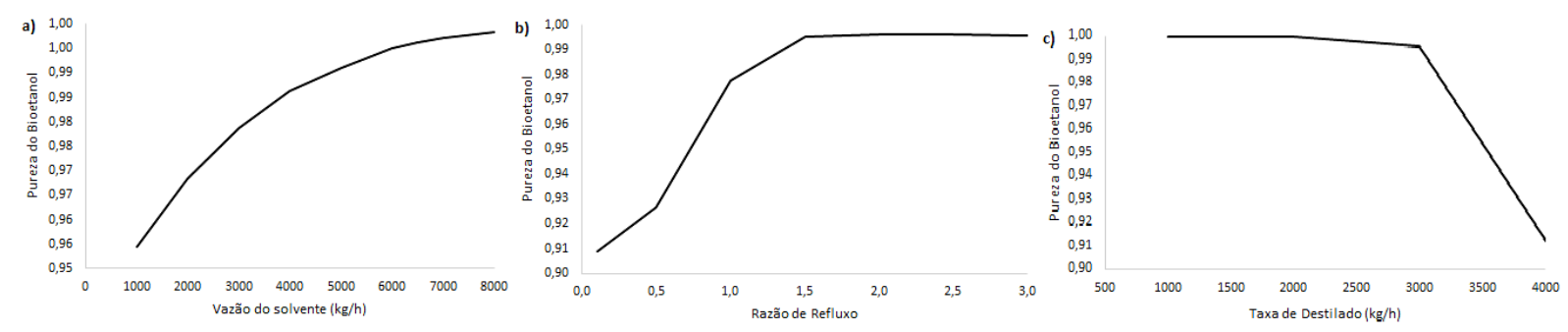

De acordo com a Figura 3a, nota-se que a vazão do solvente está diretamente relacionada com a concentração de etanol anidro obtido no topo da coluna extrativa. Conforme se aumenta a vazão de solvente há também um aumento no grau de pureza do etanol presente no destilado. Em termos numéricos, o sistema atinge 99,7\% de concentração mássica de bioetanol com uma vazão de $7000 \mathrm{~kg} / \mathrm{h}$ do líquido iônico, tendendo a tornar-se constante a pureza para vazões maiores, visto que a extração que ocorre no processo entra em estado de saturação.

Conforme a razão de refluxo é aumentada, há uma elevação na concentração mássica de bioetanol anidro no topo da coluna extrativa. No sistema, o produto atinge um valor 0,9950 de pureza para valor de razão de refluxo igual a 1,5, sendo que partir deste valor, a concentração mássica de bioetanol se estabiliza em torno de 0,9961. Portanto, razões de refluxo maiores levam a um maior enriquecimento do produto, sendo este o comportamento esperado, haja visto que a razão de refluxo é definida como a razão entre o líquido que retorna à coluna, vindo do condensador, pela vazão de destilado obtida. Logo, quanto mais líquido retorna, mais enriquecido será o produto e maior será a razão de refluxo. Porém, razões de refluxo maiores demandam uma maior carga térmica dos refervedores, tornando mais caro o produto final.

Diferentemente dos comportamentos apresentados pela vazão de solvente e razão de refluxo, o aumento da taxa de destilado reduz a concentração mássica de etanol no destilado. Para a taxa igual a $1000 \mathrm{~kg} / \mathrm{h}$, a pureza do bioetanol anidro apresenta valor igual a 0,9993 . Observa-se que a concentração de bioetanol no topo permanece quase que constante para valores de razão de destilado no intervalo de 1000 a $2000 \mathrm{~kg} / \mathrm{h}$. Já para taxa de destilado de $3000 \mathrm{~kg} / \mathrm{h}$ a diante, há uma queda acentuada na pureza de bioetanol anidro, portanto, para a obtenção de bioetanol anidro com concentração de $99,7 \%$ em massa deve-se considerar o intervalo de 1000 a $2000 \mathrm{~kg} / \mathrm{h}$.

\section{CONCLUSÃO}

A partir das simulações realizadas com o Aspen Plus ${ }^{\circledR}$ e utilizando o líquido iônico [BMIM][BF4] como solvente, foi possível identificar o ponto ótimo de cada variável e os melhores parâmetros para a destilação extrativa e consequentemente a obtenção do bioetanol 


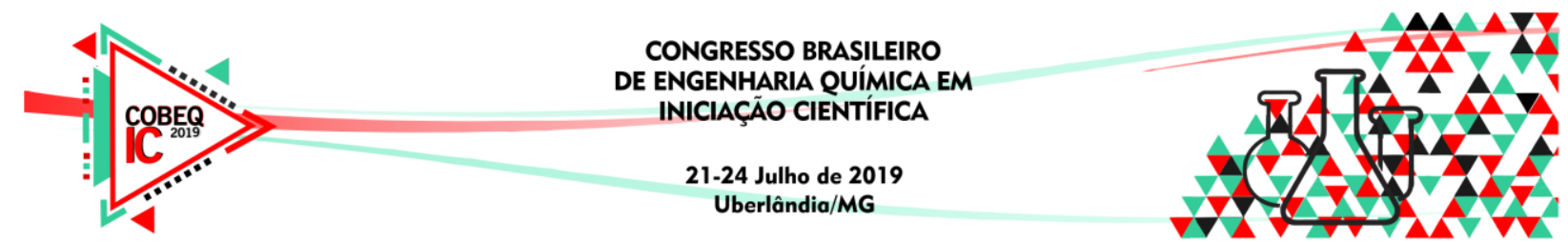

com elevado grau de pureza e com porcentagem de aproveitamento de $75 \%$ do bioetanol que é alimentado na coluna de destilação extrativa. Apesar das simulações mostrarem que, nas especificações previamente determinadas, é possível a obtenção do bioetanol com um solvente que não contribui para poluição atmosférica e com considerável eficiência de separação, a realização de uma análise de viabilidade técnica e econômica para avaliação do seu uso industrialmente é uma necessidade.

\section{REFERÊNCIAS}

EL-NAGAR, R.A.; NESSIM, M.; ABD EL-WAHAB, A.; IBRAHIM, R.; FARAMAWY, S.; Investigating the efficiency of newly prepared imidazolium ionic liquids for carbon dioxide removal from natural gas. Journ. of Mol. Liq., v. 237, p. 484-489, 2017.

HAGHIGHI, M.; NIKOOFAR, K. Nano TiO2/SiO2: An efficient and reusable catalyst for the synthesis of oxindole derivatives. Journ. of Sau. Chem. Soc, v. 20, p. 101-106, 2014.

MASSON, S. I.; COSTA, G. H.; ROVIERO, J. P.; FREITA, L. A.; MUTTON, M. A.; MUTTON, M. J.R. Produção de bioetanol a partir da fermentação de caldo de sorgo sacarino e cana-de-açúcar. Ciê. Rur., v. 45, p. 1695 - 1700, 2015.

MATUGI, K. Produção de etanol anidro por destilação extrativa utilizando soluções Salinas e glicerol. Diss. UFSCar, 2013.

ROCHA, L. B.; MOREIRA, W. M.; LIMA, O. C. M. Simulação Rigorosa de Colunas de Destilação em Aspen Plus® para Produção de Etanol Hidratado e Etanol Anidro. An. do III Enc. de Pes da Fateb, v. 2, p. 491-511, 2016.

SOUZA, W. L. R.; SILVA, C. S.; MELEIRO, L. A. C.; MENDES, M. F.; CHEM, J. Vaporliquid equilibrium of the (water + ethanol + glycerol) system: Experimental and modelling data at normal pressure. Therm., v. 67, p. 106-111, 2013.

ULLMANN, F.; ELVERS, B. Ullmann's encyclopedia of industrial chemistry. 7 ed., v. 40, Weinheim, Germany: Wiley-VCH, 2011.

ZANARDI. S. M.; JUNIOR, F. C. E. Tecnologia e perspectiva da produção de etanol no Brasil. Rev. Lib., v. 17, p. 01-118, 2016.

ZHU, Z.; RIA, Y.; LI, M.; JIA, H.; WANG, Y. Extractive distillation for ethanol dehydration using imidazolium-based ionic liquids as solvents. Chem. Eng. and Proc., v. 109, p. 190-198, 2016.

ZUBIR, M. A.; RAHIMI, A. N.; ZAHRAN, M. F. I.; SHAHRUDDIN, M. Z.; IBRAHIM, K. A.; HAMID, M. K. A. Systematic design of energy efficient extractive distillation column for azeotrope mixture. En. Proc., v. 142, p. 2636-2641, 2017. 